\title{
¿Hay también progreso en el infierno? La hipótesis del P. Luis G. Alonso Getino
}

\author{
LEOPOLDO QUILEZ FAJARDO \\ Facultad de Teología San Vicente Ferrer (España) \\ leoquilez@gmail.com
}

\begin{abstract}
Resumen
En el ámbito de la escatología, el tema del infierno es uno de los más insondables para el fiel cristiano. Desde la perspectiva creyente el peor de los males posibles es la muerte eterna. En ella, y de forma irrevocable, la criatura queda encerrada en su dolorosa automarginación. Esta posibilidad hace tambalearse las nociones de justicia y, sobre todo, de misericordia divina, así como la eficacia de la salvación cristológica. Desde estas intuiciones, el P. Luis Alonso Getino, apoyándose principalmente en la Escritura, la praxis litúrgica y la autoridad de Santo Tomás, arriesgó una hipótesis, que salvaguardando la posibilidad humana del non serviam absoluto, trata principalmente de mantener incólume la bondad de un Dios que permanecería fiel a su esencia de la única manera posible, a saber, suavizando las penas eternas en progresivo lenitivo. Así, dignidad humana y divina quedan protegidas en una vanguardista y sugerente teología.
\end{abstract}

Palabras clave: infiermo, misericordia divina, justicia, culpabilidad, condena eterna.

\section{Is there also any progress in hell? The hypothesis of P. Luis G. Alonso Getino}

\begin{abstract}
Talking about christian eschatology, one of the most unfathomable subjects for faithful is hell. Eternal death is the worst possible evil for believers. In it, and irrevocably, the creature is locked in her painful self-rejection. This possibility shakes the notions of justice and, above all, divine mercy, and the effectiveness of Christological salvation. From these intuitions and mainly supported by Scripture, liturgical practice and the authority of St. Thomas, P. Luis Alonso Getino ventured a guess, preserving the human possibility of the complete non serviam. It primarily deals with keeping intact God's goodness, who would remain faithful to His essence the only way possible, namely, smoothing soothing progressive eternal punishment. Thus, divine and buman dignity are protected in a modern and suggestive theology.
\end{abstract}

Key words: hell, divine mercy, justice, guilt, eternal damnation.

Doctor en Sagrada Teología por la Facultad de Teología «San Vicente Ferrer» de Valencia (España). Profesor de la misma Facultad, así como Profesor de Escatología en el Instituto Superior de Ciencias Religiosas a Distancia «San Agustín» (Valencia). Entre sus publicaciones destaca «El Estado Intermedio en la liturgia contemporánea» (2003), «El Magisterio y la escatología de doble fase» (2003) y ¿Contemplación o progreso? Dos formas de concebir la vida eterna en la Historia de la Teología (2007).

En buena medida el presente trabajo constituye el reverso «negativo» de otro artículo publicado anteriormente en esta misma revista con el título "El cielo, el milagro de la primera vez. Incomprensibilidad divina y beatitud humana en la tradición teológica”, Veritas, № 18 (Marzo 2008), 151-181, en el que abogaba por la concepción dinámica de la vida eterna. 


\section{El punto de partida: la conjunción entre la justicia y la misericordia divina en el éschaton}

El dominico español Luis G. Alonso Getino (1877-1946), basándose principalmente en Sto. Tomás, publicó en 1934 un libro, de formato dialógico entre un alumno y su maestro, cuyo título fue Del gran número de los que se salvan y la mitigación de las penas eternas. ${ }^{1}$. En él, entre otras ideas, postula una arriesgada hipótesis a propósito de la atenuación de las penas de los condenados en el infierno, tema que suscitó, más que el resto de su obra, un amplio debate en el panorama teológico contemporáneo ${ }^{2}$. Dicha hipótesis puede encajar como la otra cara del dinamismo escatológico, pues de alguna manera también se puede presentar como un movimiento, si bien, éste dista mucho de ser el de aquellos que crecen en la vida con mayúsculas. Efectivamente, en el escrito de Alonso Getino podemos advertir un tipo de progreso que conduce de la mayor pena a la menor. Podría pensarse que la lógica de este pensamiento nos llevaría a la apocatástasis, condenada por la Iglesia ${ }^{3}$, pero no se corre ese riesgo herético si aducimos que esa disminución paulatina sólo afecta, según la interpretación clásica, a lo «accidental» del infierno (pena de sentido, de índole más material y que nos remite al fuego) y no a lo «sustancial» de éste (pena de daño o privación de la visión de Dios). De esta forma, no consideramos desacertada la opinión del P. Sauras cuando afirma que no es inconciliable esta doctrina con la recta ortodoxia ${ }^{4}$.

El problema radical es la aparente incompatibilidad entre la misericordia divina y la ineluctabilidad del castigo por culpas históricas:

En realidad, lo que yo no acierto a comprender, más bien que el género de castigo (que será el que Dios disponga y tan justo como la culpa exija), es la inexorabilidad de él, la eterna y nunca disminuida expiación, tan desproporcionada a la Misericordia de Dios y a lo pasajero de la culpa. Esa obligación en que ciertos escolásticos ponen a Dios, metiéndole en un

1 Nosotros citaremos, por parecernos más completa, la segunda edición: L. G. Alonso Getino: Del gran número de los que se salvan y de la mitigación de las penas eternas. Diálogos. Feda, Madrid-Valencia 1936.

2 Para una presentación más amplia del autor y de la obra, cfr. M. GELABERT BALLESTER: "La misericordia se siente superior al juicio. Relectura de una hipótesis del P. Getino", Teología Espiritual (septiembre-diciembre 2000), 261-307.

Cfr. H. Denzinger - P. Hünerman: El Magisterio de la Iglesia. Enchiridion Symbolorum Definitionum et Declarationum de rebus fidei et morum, Herder, Barcelona 1999 (en adelante DH), 411.

4 E. SaUras: "La misericordia de Dios y los condenados según la mente de Santo Tomás”, La Ciencia Tomista 154 (julio-agosto 1935), 39. 
puño, en la necesidad imprescindible de castigar sin la menor remisión, como si no hubiera él formado sus criaturas para galardonarlas más bien que para castigarlas. ¡como si él dejara de ser Padre de todos los mortales, por desventurados y pecadores que ellos sean! Esa especie de cambio de las divinas propiedades es lo que yo no acierto a coordinar en estos misterios de expiación, que, por otro lado, venero y defiendo sin réplica 5 .

Nos encontramos de lleno en el polémico cotejo de los atributos divinos de justicia y misericordia; nuestro autor se inclina sin rodeos por la primacía de la segunda, merced al peso victorioso de la economía de salvación culminada en Cristo y prolongada en su Iglesia:

En el plano de justicia, al pecado debe seguir el abandono de Dios, la detestación y la condena. En plano de misericordia, la compasión, el perdón y la ayuda. Nuestro Señor no quiere la muerte del pecador, sino que se convierta y viva. Ese querer de Dios no va a quedarse en agua de borrajas; en una frase amable; en aire solano. Él nos ha hecho; no nos hicimos nosotros mismos (Sal 99). El sabe mejor que nosotros que hemos sido concebidos en pecado (Sal 50). En su previsión entra nuestra debilidad, nuestra inconsustancia, nuestra ignorancia, nuestra malicia. Y si ésta es mucha y grava en el platillo adverso de la justicia, en el otro platillo quiso Él poner el peso de su Sangre Divina. Nosotros tenemos los sacramentos para lo que pudiéramos llamar aplicación material del precio de esa Redención; a Dios le quedan los mil y un recursos de aplicarlo por caminos ocultos a nuestras miradas. Del hecho no es posible dudar; el modo nos debe importar poco; es objeto de curiosidad más que de utilidad ${ }^{6}$.

El atributo fontal y motriz de Dios es, para el dominico español, la misericordia eterna, que mueve y sostiene todo el obrar divino por siempre $y$, por ende, sea cual fuere la situación en la que se halle inmersa su criatura, también en la de mayor desdicha:

La naturaleza de nuestro Dios, Padre nuestro siempre, Misericordioso siempre, no se cambia con nuestras ingratitudes. Él, que es todo amor, exhala misericordias hasta en el momento del castigo, y detiene y anula en cierto modo su sentencia ante las oraciones de los Santos ${ }^{7}$.

Y si arguyera también alguno que la eternidad y Misericordia, que defendemos como inseparables de Dios, con nuestra manera de pensar

5 L. G. Alonso Getino: Del gran número de los que se salvan y de la mitigación de las penas eternas. Diálogos, 126-127.

$6 \quad$ Ibíd., 101; cfr. también 289.

7 Ibíd., 166-167. 
sólo conseguimos que se prolonguen hasta el día del Juicio; porque desde ese día empezará Dios a ser mero ajusticiador de los condenados, no teniendo para ellos un signo de paternidad o de misericordia, puesto que en ese día cesarán las mitigaciones y todo será para ellos invariable y horrible desdicha, al que arguyera así responderíamos que la sentencia se da por terminada en ese día terrible, pero las mitigaciones acordadas continuarán perpetuamente; porque la misericordia de Dios es eterna, está sobre todas sus obras y en todas late. El infra condignum en la sanción divina es modalidad permanente, y todas las aguas salobres de las ofensas no podrán extinguir la caridad, ni los ríos de las iniquidades la cubrirán8.

\section{El fundamento bíblico y litúrgico}

Las intuiciones anunciadas, amén de la Sagrada Escritura', las fundamenta nuestro autor en una doble, y desigual en cuanto a valor según nuestro juicio, basamento, a saber: litúrgico y de autoridades. Será este último, y en lo que atañe a Santo Tomás, el referente más sólido de sus especulaciones. Empecemos, por el apoyo más censurable, por cuanto hace de él una lectura maximalista que no parece concordar con la intención de los textos litúrgicos, que más bien aluden a la intercesión por quienes tienen algo que purgar y no de quienes ya se hallarían de hecho en el infierno ${ }^{10}$ :

De lo cual se deduce que lo de hacer oración por los condenados del infierno en orden a aliviarlos de las penas accidentales o de sentido fue algo general, no sólo en la iglesia griega, sino también en la latina...Las fórmulas litúrgicas anteriores a 1570 y las nuestras son doctrinalmente las mismas. Tanto monta que se pida al Señor alivie en el infierno las penas de los que no pueden salir de él, como que se pida indulgencia y perdón para todos los pecados, como que se diga, como se dice, al consumir el cuerpo del Señor que el sacrificio de la Misa sea propiciatorio por todos lo que se bubiere ofrecido-omnibus pro quipus illud obtuli, sit te miserente, propiciabile. Con respecto a la mitigación general y hasta extinción de penas al descender Jesús a los infiernos, hay antigua y larga sarta de autoridades, contándose entre ellas la de nuestro Sacramentario Muzárabe...; y para salvar un fondo de verdad en las plegarias de los sacramentarios griegos, que a veces apuntan a la supresión de toda pena para la generalidad de los damnados, ya que no para todos,

$8 \quad$ Ibíd., 263-264.

$9 \quad$ Por ejemplo Is 49,15; Job 25,3; Sal 145,8-9; cfr. L. G. AlOnSO GeTino: Del gran número de los que se salvan y de la mitigación de las penas eternas. Diálogos, 165-166.

10 Cfr. M. Gelabert BALlester: "La misericordia se siente superior al juicio. Relectura de una hipótesis del P. Getino”, 297. 
como en la apocatástasis origenista. Salvando la doctrina de la mitigación, aunque no se defienda la exactitud de sus fórmulas, se puede defender la seriedad de sus plegarias, lo que tratándose de iglesias tan numerosas, tan antiguas y tan amantes de la tradición, importa grandemente... en la Liturgia hay también abundantes textos, sin esa doctrina, inexplicables. Bastenos dos: Dios, de quien es propio tener misericordia siempre y perdonar... Dios, cuyo poder principalmente se muestra perdonando... ${ }^{11}$.

\section{E1 fundamento de tradición teológica: Sto. Tomás de Aquino}

Como hemos señalado, el segundo recurso del que se vale Alonso Getino para avalar su hipótesis es el de las citas de autores santos o insignes en la historia del cristianismo que se hayan pronunciado en su línea argumental:

Mientras algunos rigoristas dan a entender que Dios deja de ser Padre y Misericordioso con los condenados y que aquella sentencia divina: nibil odisti forum quae fecisti - nada odiaste de lo que criaste - no tiene ya sentido, paladeemos nosotros aquellas palabras de San Francisco de Sales en el Tratado del amor de Dios: ¡cuán bueno sois, Señor!, pues aun en lo más fuerte de vuestra ira, no podéis contener el torrente de vuestras misericordias, ni impedir que entren sus aguas benéficas en las impetuosas llamas del infierno. El texto de san Francisco parece inspirado en este otro de una santa italiana de gran autoridad: la pena de los réprobos no es infinita en su rigor, porque la inmensa Bondad de Dios hace penetrar hasta el fondo de los Infiernos los rayos de su Misericordia. Si no escuchase Dios más que su Justicia, expirando el pecador en estado de pecado mortal, sufriría una pena infinita en intensidad, si su naturaleza fuese capaz, de pena infinita en intensidad. Pero la Divina Misericordia modera la atrocidad del suplicio merecido y no le deja de infinito más que la duración. (Santa Catalina de Génova. El Purgatorio). El mismo Bossuet, que era tan severo teólogo y tan rigorista en esta parte, discutiendo la sentencia del benedictino P. Lami sobre la eficiencia de la Pasión de Cristo con respecto a los condenados, llega a esta confesión: si el autor se ciñera a defender que Dios, por amor a Jesucristo, castiga a los condenados y a los mismos demonios menos de lo que se merecen, no me opondría a ello, según lo que abora entiendo. Todo ello no es más que repetir en espíritu el citra condignum puniuntur, non quod a poena totaliter absolvantur de Santo Tomás ${ }^{12}$.

11 L. G. Alonso Getino: Del gran número de los que se salvan y de la mitigación de las penas eternas. Diálogos, 163-166.

12 Ibíd., 262-263. 


\subsection{La misericordia divina "punit citra condignum»}

De la mano de esta última cita nos adentramos en el más importante soporte que la tradición teológica ofrece a Alonso Getino, esto es, el pensamiento de Santo Tomás de Aquino ${ }^{13}$.

-El Aquinate no afirma nunca que se dé aminoramiento de la pena (ni en su intensidad, según la malicia del pecado, ni en su duración, que es la eternidad) por obra de la divina justicia. Este hecho significaría la disminución de la culpa o la posibilidad de merecer en el ya condenado:

Como la pena tenga una doble cantidad, a saber, según la intensidad del dolor y según la duración del tiempo, la cantidad de la pena corresponde a la cantidad de la culpa conforme a la intensidad del dolor, de suerte que se inflige una pena mayor a quien pecó más gravemente ${ }^{14} \ldots$ Del mismo modo, según la justicia divina, uno se hace digno por el pecado de ser totalmente separado del consorcio de la ciudad de Dios; lo cual tiene lugar en todo pecado que se comete contra la caridad. Y así, por el pecado mortal, que es contrario a la caridad, es uno arrojado para siempre de la sociedad de los santos al serle impuesta pena eterna ${ }^{15}$.

-Ahora bien, Dios siempre castiga menos de lo que el pecador merece, ya que su justicia siempre va acompañada de su misericordia. Ésta en todo momento premia más de lo merecido y, sobre todo, castiga menos de lo debido. Ella se manifiesta siempre castigando citra condignum y no de otra forma:

Dios, al obrar misericordiosamente, no actúa contra, sino por encima de la justicia. Ejemplo: si a quien se le debe cien denarios se le dan doscientos, quien hace esto no es injusto, sino que obra libre y misericordiosamente. Lo mismo sucede cuando se perdonan las ofensas recibidas. Pues quien algo perdona, algo da. Por eso el Apóstol, al perdón le llama don cuando dice en Ef 4, 32: Daos unos a otros como Cristo se dio a vosotros. Queda claro, así, que la misericordia no anula la justicia, sino que es como la plenitud de la justicia. Por eso se dice en Sant 2, 13: la misericordia hace sublime el juicio ${ }^{16}$.

13 Cfr. E. SAuras: "La misericordia de Dios y los condenados según la mente de Santo Tomás”, 5-39.

14 De ahí las declaraciones del II de Lyon y del Florentino respecto a las «penas desiguales»; cfr. DH 858 y 1306, respectivamente.

15 T. DE Aquino: Suma de Teología, Supl., q. 99, a. 1.

16 T. DE AQuino: Suma de Teología, I, q. 21, a. 3., ad. 2. 
Algunas obras son atribuidas a la justicia y otras a la misericordia, porque en algunas aparece con más relevancia la justicia; en otras la misericordia. $\mathrm{Y}$, sin embargo, en los condenados aparece la misericordia no porque les quite totalmente el castigo, sino porque se lo alivia, ya que no los castiga como merecen. Y en la justificación del pecador aparece la justicia, pues quita la culpa por amor, el mismo amor que infunde misericordiosamente ${ }^{17}$.

-El citra condignum de Santo Tomás puede entenderse, no sólo como la acción de la misericordia que en el momento de imponer la sentencia sanciona menos de lo que el pecador merece, sino también, en la clave de nuestro autor y del último texto del Aquinate, es decir, aliviando las penas a lo largo de la condena ${ }^{18}$ hasta el límite que Dios quiera o que Él mismo se haya permitido. Rematemos la cuestión con otro fragmento del santo:

$\mathrm{Y}$, en efecto, otros dicen que la pena de la cual alguien es deudor, después de perdonada la culpa, se le castiga temporalmente en el infierno. Sin embargo, de ahí no se sigue que haya redención en el infierno, porque la pena que se absuelve no se redime. Sin embargo, no hay inconveniente que, en cuanto a lo accidental, la pena del infierno disminuya o aumente hasta el día del Juicio Universal ${ }^{19}$.

-La mitigación de las penas no es ilimitada. En lo que dice a la intensidad siempre existirá correspondencia con la gravedad del pecado; en lo que atañe a la temporalidad nunca cesará el castigo:

Mas esta opinión parece oponerse a la providencia divina, que nada dejó desordenado en las cosas. Pues la culpa no queda ordenada sin la pena, y por lo tanto, no puede ser que sea quitada la pena si antes no se expía la

17 Cfr. T. DE Aquino: Suma de Teología, I, q. 21, a. 4., ad. 1. Aunque estos textos no son citados expresamente por Getino, implícitamente hallamos su espíritu a lo largo de sus diálogos; cfr. L. G. Alonso GETINO: Del gran número de los que se salvan y de la mitigación de las penas eternas. Diálogos, 127; 288-289; 318-319; 397.

18 Para Getino está claro, en polémica con otros teólogos, que la pena que puede aliviarse no es solamente la de los pecados veniales, ni la temporal de los mortales ya perdonados, sino la de todos los pecados, incluso la de los mortales no perdonados. Cfr. L. G. Alonso Getino: Del gran numero de los que se salvan y de la mitigación de las penas eternas. Diálogos, 397.

19 T. De Aquino: IV Sent., dist. 22, q. 1, a. 1, ad. 5.; L. G. Alonso Getino: Del gran número de los que se salvan y de la mitigación de las penas eternas. Diálogos, 128. 
culpa. Y como la culpa permanece siempre en los precitos en manera alguna su pena se interrumpe ${ }^{20}$.

Dios, por su parte, se compadece de todos. Pero como su misericordia está regulada por el orden de su sabiduría, de ahí que no la extienda a algunos que se hicieron indignos de ella, como a los demonios y condenados, que están obstinados en su malicia. Sin embargo, en ellos tiene también lugar la misericordia, en cuanto son castigados menos de lo que se merecen, no que sean librados totalmente de la pena ${ }^{21}$.

- Como quiera que Dios no está sometido a ley, tampoco lo está su misericordia y, en esta óptica, el propio Santo Tomás admite la sorprendente y excepcional posibilidad de la liberación del infierno, en concreto de Trajano por las oraciones de san Gregorio:

Del suceso de Trajano $^{22}$ puede probablemente pensarse que fuera resucitado por las preces del bienaventurado Gregorio y así consiguiera la gracia y con ella la remisión de los pecados y, consiguientemente, la inmunidad de la pena; lo mismo que acontece en todos los que fueron milagrosamente resucitados, de los cuales consta que muchos fueron idólatras y condenados ${ }^{23}$.

\subsection{Las causas de la mitigación de las penas}

Para retomar el hilo argumental de la mitigación de las penas, hemos de concluir que para Sto. Tomás ésta se debe a una triple etiología, que, en el fondo, se reduce a la última:

a) La bondad de Dios que no deja sin «recompensa» cualquier obra buena que el condenado hiciera en esta vida:

No puede darse puro el mal sin mezcla de bien alguno. Por lo tanto, quienes han de ser trasladados a la bienaventuranza, que es el bien sumo, sin mezcla de mal alguno, deben estar limpios de todo mal. Por lo cual, es menester que haya un lugar donde se purifiquen si de aquí no salieron del todo limpios. Mas los que sean sepultados en el infierno no estarán

20 Tomás de Aquino, Suma de Teología, Supl. 71, 5.

21 Tomás De Aquino, Suma de Teología, Supl. 99, 2., ad. 2; cfr. Supl. 99, 4.; L. G. Alonso Getino: Del gran número de los que se salvan y de la mitigación de las penas eternas. Diálogos, 263.

22 T. DE AQuino: Suma de Teología, Supl. 71, 5, ob. 5.

23 T. De Aquino: Suma de Teología, Supl. 71, 5, ad. 5; L. G. Alonso Getino: Del gran numero de los que se salvan y de la mitigación de las penas eternas. Diálogos, 314-3165. 
inmunes de todo bien y por eso no es lo mismo porque allí en el infierno pueden recibir el premio de sus buenas obras, en cuanto que estos pasados bienes les sirven para la mitigación de la pena ${ }^{24}$.

Un razonamiento similar, aunque de «dirección» opuesta, lleva al dominico español a referirse a las consecuencias ultraterrenas de los pecados cuyas secuelas mundanas siguen perpetuándose, especialmente en los llamados pecados de escándalo. Aunque es un tema marginal en el conjunto de su obra añade una perspectiva no desdeñable y de actualidad teológica $^{25}$ :

Yo me figuro las penas de sentido como las aguas de un depósito, cuya cantidad pende, por una parte, de la evaporación, que tiende a darles fin, y, por otra parte, de las bocas de entrada y de salida, que según su calibre, hacen subir y bajar el nivel, o lo mantienen fijo, si ambas afloran por igual. En la evaporación me imagino la misericordia del Señor, que mediante el calor de la redención penetra hasta el báratro, aceptando la mediación caritativa de los que peregrinamos por el mundo. Si allí no resonara más historia que la de los sufragios, siendo estos tan insistentes por parte de la Iglesia, y de muchos particulares, iríamos, efectivamente, al borde del agotamiento — nunca al fin - de la pena llamada de sentido. Por desgracia, gran parte de los pecadores son reos de pecado de escándalo, y sus penas tendrán que parecerse a las aguas tristes del Mar Muerto. Contará éste sólo con la absorción de las puras corrientes del Jordán, y sus aguas fueran dulces como las del lago del Tiberiades, que de ellas se alimenta; pero de las entrañas mismas del Mar Muerto sale el asfalto, que las embetumina, y con ser ellas puras, de suyo, y tan alta su temperatura y tantísima su evaporación, ni cambian de nivel, ni dejan de ser ardientes, cáusticas y $\operatorname{amargas}^{26}$.

b) La caridad de la Iglesia militante concretada en los sufragios ${ }^{27}$ :

24 T. DE Aquino: Suma de Teología, Supl. 69, 7, ad. 9; L. G. Alonso Getino: Del gran número de los que se salvan y de la mitigación de las penas eternas. Diálogos, 265.

25 Cfr. M. Gelabert Ballester: "La misericordia se siente superior al juicio. Relectura de una hipótesis del P. Getino", 298.

26 L. G. Alonso GeTino: Del gran número de los que se salvan y de la mitigación de las penas eternas. Diálogos, 176-177.

27 Se trata de una cuestión ambigua en la presentación de Sto. Tomás, si bien parece que su conclusión es negativa, es decir, que estos no aprovechan para los moradores del infierno (cfr. Suma de Teología, Supl. 71, a. 5). Sin embargo puede darse también una lectura menos restrictiva, como la que hace el propio L. G. Alonso GeTino: Del gran número de los que se salvan y de la mitigación de las penas eternas. Diálogos, 140-143; Cfr. M. GELABERT BALLESTER: "La misericordia se siente superior al juicio. Relectura de una hipótesis del P. Getino", 299. 
Con todo no hay que creer que los sufragios de los vivos les sirvan para mudar su estado de condenación en el de bienaventuranza o al contrario; pero sí les sirven para la disminución de la pena u otra cosa tal que no haga cambiar el estado del muerto ${ }^{28}$.

c) La misericordia divina raíz de su obrar y el atributo por excelencia de su ser, que sobrepuja su justicia y lo mueve siempre al exceso donativo:

La obra de la justicia divina presupone la obra de misericordia, y en ella se funda, pues a la criatura no se debe algo, a no ser por algo preexistente o presupuesto; incluso esto se deberá también por algo previo. Y como no se puede llevar un proceso indefinido, es necesario llegar a algo que dependa de la exclusiva bondad de la voluntad divina, que es el fin último... De este modo, en cualquier obra de Dios aparece la misericordia como raíz. Y su eficacia se mantiene en todo, incluso con más fuerza, como la causa primera, que actúa con más fuerza que la causa segunda. Por eso, también lo que se debe a alguna criatura, Dios, por su misma bondad, lo da con más largueza que la exigida por lo debido. Pues para mantener un orden justo se necesita mucho menos de lo que la bondad divina otorga y que sobrepasa toda proporción exigida por la criatura ${ }^{29}$.

El propio Alonso Getino nos hace un perfecto resumen de todo cuando venimos presentando relativo a Sto. Tomás:

Bien redondeada queda con eso la doctrina de la mitigación de penas infernales, por lo menos hasta el día del Juicio Universal, puesto que se pueden deducir: a) por la Misericordia del Señor, que prevalece contra su Justicia, que es como decir por la Paternidad eterna de Dios; b) por las oraciones y sacrificios de los vivos; c) por las buenas obras que los mismos condenados practicaron en vida. Ni Dios deja de ser Padre, ni las buenas obras dejan de aprovechar, ni los sufragios son inútiles en el lugar de expiación. El veto que pone Santo Tomás es sencillamente el que está puesto en la revelación y el que exige la Justicia Divina: non quod a poena totaliter absolvantur. Eso no, las penas que Dios ha declarado eternas en la Santa Escritura, eternas hemos de declararlas todos; eternas han de ser, si Él, por un acto de su poder absoluto, no modifica esa sentencia ${ }^{30}$.

\footnotetext{
28 T. DE AQuino: Suma de Teología, Supl. 71, 2.

29 T. DE AQuino: Suma de Teología, I, q. 21, a. 4.

30 L. G. Alonso Getino: Del gran número de los que se salvan y de la mitigación de las penas eternas. Diálogos, 288-289. Nótese la finura del final de la cita, que viene a ser un elegante modo de dejar las «puertas abiertas» al poder misericordioso de quien es el Señor.
} 
La analogía del penal ilustra muy bien su pensamiento, que afirma el hecho de la atenuación, pero que apenas se atreve a imaginar el cómo, pues ésta ya linda con el misterio de la misericordia absoluta ${ }^{31}$ :

No es posible averiguar el modo ni el tiempo, si Dios no lo revela, ni es tampoco discreto darse a imaginar posibles modos de remisión, que no tendrán más probabilidad de ser los verdaderos que otros infinitos análogos. En un penal -ya lo hemos dicho-, conservando lo substancial del encarcelamiento, hay en diversos días asuetos y extraordinarios; hay, pasado ciertos meses, mejoras de habitaciones, de vestido, etc. Las sanciones mitigadoras establecidas el día del Juicio Universal, no sabemos si serán continuas o si serán periódicas, respondiendo quizá a efemérides gloriosas de nuestra Redención, a aniversarios de obras buenas practicadas por el interesado o por los que pidieron por él en caridad... De eso nada podemos afirmar; ni siquiera hasta qué punto se mitigará con la condena la desesperación del condenado; que aunque propendemos a considerarla como una desesperación máxima, de su peso se cae que será de distinto calibre, conforme a los deméritos. Lo que sí importa subrayar es que si bien los castigos exigidos por la Justicia Divina se han de cumplir inexorablemente, las mitigaciones de la Misericordia igualmente se implantarán ${ }^{32}$.

\section{Balance y contextualización de la hipótesis en el marco del dinamismo escatológico}

Haciendo un balance de la hipótesis de Luis G. Alonso Getino afirmamos que, aunque estando contextualizada en la escatología clásica de la muerte eterna, exhibe un gran sentido común y una genuina sensibilidad bíblica que, paradójicamente la convierten en progresista para su época e incluso para nuestros días. Pondera perfectamente el misterio de la libertad del hombre para el mal con el mayor de la misericordia divina, salvaguardando con optimismo la ortodoxia. Nos parece afortunado pensar que, en el caso de que el mysterium iniquitatis, en lo que concierne a la responsabilidad humana, hiciera inútil para algunos la obra de la salvación-redención, éste siempre será incapaz de ir mucho más allá, a saber, de anular la esencia amorosa y, por ende, perdonadora, de Dios. Tal vez, Dios no pueda cambiar la naturaleza del hombre obstinado en el pecado, pero lo que nos parece incontestable es que jamás el pecador podrá mutar la naturaleza misericordiosa del Señor. Esa

\footnotetext{
31 Ibíd., 263.

32 Ibíd., 265.
} 
imposibilidad hace atendible las conjeturas de Alonso Getino. Finalmente, la obra analizada nos descubre de forma indirecta, que el verdadero horror del infierno es la pérdida de Dios ${ }^{33}$, pues está no halla mitigación y constituye la auténtica quiebra de lo humano ${ }^{34}$.

Como contrapartida al «dinamismo ascendente» ${ }^{35}$ de Alonso Getino, y como quiera que la ausencia absoluta de Dios nos llevaría a la hipótesis, no aceptada por el Magisterio, de la aniquilación del hombre ${ }^{36}$, pues la criatura sin el creador se esfuma ${ }^{37}$, no debemos descartar el «dinamismo descendente»; se trataría del paulatino endurecimiento y alejamiento de Dios, sin lograrlo nunca del todo ${ }^{38}$, debido a la aversión acumulada y creciente del impío. Esta segunda posibilidad, ajena a Alonso Getino, también lo es a quien esto escribe.

Llegados aquí, lo expuesto no es óbice para que nos inclinemos a suscribir una de las hipótesis más modernas del infierno, aquella que la contempla como posibilidad real, pero no necesariamente consumada, la que aboga por el derecho a esperar por todos ${ }^{39}$. Optimismo soteriológico muy próximo al del autor que nos ha servido de guía en este apéndice: « $\mathrm{O}$ h, misericordia de Dios! ¿No sería ofenderos cerrar mi alma a esa esperanza?» ${ }^{40}$.

33 Cfr. M. Gelabert BALlester: "La misericordia se siente superior al juicio. Relectura de una hipótesis del P. Getino", 302.

34 El propio teólogo dominico, en otro alarde de vanguardismo, propone la derivación de la pena de sentido de dicha privación divina. Cfr. L. G. Alonso Getino: Del gran número de los que se salvan y de la mitigación de las penas eternas. Diálogos, 187.

35 Utilizamos aquí este «vocablo topográfico» por su capacidad evocadora. Queremos significar con él el proceso de alivio que supone la presencia divina respecto del dolor del condenado, quien, de alguna manera, es «elevado» a cotas de menor sufrimiento por Dios (siempre imaginado en «lo alto»).

36 Cfr. E. SCHILLEBEECKX: Los hombres relato de Dios. Sígueme, Salamanca 1994, $210-$ 215; A. Tornos: Escatología, vol. II, UPCO, Madrid 1991, 226-231; M.-É. BOISMARD: ¿Es necesario hablar aún de resurrección? Desclée de Brower, Bilbao 1996, 145-146.

37 Gaudium et Spes 36.

$38 \mathrm{Al}$ respecto, véase el acompañamiento silente de Cristo crucificado en el infierno, M. KEHL: ¿Y después del fin qué? Del fin del mundo, la consumación, la reencarnación y la resurrección. Desclée de Brower, Bilbao 2003, 297-298.

39 Cfr. H. URs vON BaLthasar: Tratado sobre el infierno. Edicep, Valencia 2000, 136137 y $170-173$.

40 L. G. Alonso GeTino: Del gran número de los que se salvan y de la mitigación de las penas eternas. Diálogos, 69. 
Sumario: 1. El punto de partida: la conjunción entre la justicia y la misericordia divina en el éschaton; 2. El fundamento bíblico y litúrgico; 3. El fundamento de tradición teológica: Sto. Tomás de Aquino; 3.1. La misericordia divina «punit citra condignum»; 3.2. Las causas de la mitigación de las penas; 4. Balance y contextualización de la hipótesis en el marco del dinamismo escatológico. 